\title{
具有室温延展性的新型无机半导体材料: $\alpha-\mathrm{Ag}_{2} \mathrm{~S}$
}

\author{
李秋珵，孙靖宇*
}

苏州大学能源与材料创新研究院, 苏州 215006

* 联系人, E-mail: sunjy86@suda.edu.cn

在传统材料中, 金属材料和合金具有室温延展性, 金 属键在外力作用下可以产生塑性形变, 其形变张力可达 $5 \%$ 100\% $\%^{[1,2]}$. 而无机半导体材料和陶瓷绝缘材料通常都 属于脆性材料, 只有不到 $0.1 \% \sim 0.2 \%$ 的形变张力.

中国科学院上海硅酸盐研究所陈立东和史迅研究组 与德国马普所Yuri Grin研究所 ${ }^{[3]}$ 合作, 首次报道了一种在 室温条件下具有类似金属的优异延展性的无机半导体材 料: $\alpha-\mathrm{Ag}_{2} \mathrm{~S}$. 其具有反常于常规无机半导体材料的力学性 能, 特别是拥有良好的可延展性及弯曲性, 有望在柔性电 子学领域获得广泛应用, 相关研究2018年4月9日在线发表 于Nature Materials ${ }^{[3]} . \alpha-\mathrm{Ag}_{2} \mathrm{~S}$ 晶体在室温下具有锯齿形的 褶皱层状单斜结构, 带隙约 $1.03 \mathrm{eV}$; 其室温电导率 0.09 0.16 S m$~_{-1}$, 且电性能在半导体区间可实现自由调控.
Shi等人 ${ }^{[3]}$ 通过铸锭浇注法和放电等离子烧结法制备得到 $\alpha-\mathrm{Ag}_{2} \mathrm{~S}$ 体相材料. 他们发现这种 $\alpha-\mathrm{Ag}_{2} \mathrm{~S}$ 材料的延展性比其 他半导体提高了几个数量级, 甚至优于一些合金材料, 其 拉伸张力可达 $4.2 \%$, 压缩张力高达 $50 \%$ 以上, 弯曲张力超过 20\%(图1); 而传统的半导体材料通常难以承受任何塑性形 变. 具有优异延展性的 $\alpha-\mathrm{Ag}_{2} \mathrm{~S}$ 材料的发现则打破了半导体 材料脆性的定律.

$\alpha-\mathrm{Ag}_{2} \mathrm{~S}$ 材料的优异延展性主要是源于其本征的结构 和化学键. 满足延展性的条件主要有 2 点：(1) 可以实现原 子、缺陷或者界面沿特定晶面的滑移(具有较小的滑移能垒 $\left.\Delta E_{\mathrm{B}}\right) ;$ （2）滑移面内具有相对强的原子间作用力以保证材 料的完整性(具有较大的分裂能 $\Delta E_{\mathrm{C}}$ ). 综合来看, $\alpha-\mathrm{Ag}_{2} \mathrm{~S}$ 具 有很小的滑移势垒和较大的分裂能, 使得它具有优异的延 (a)
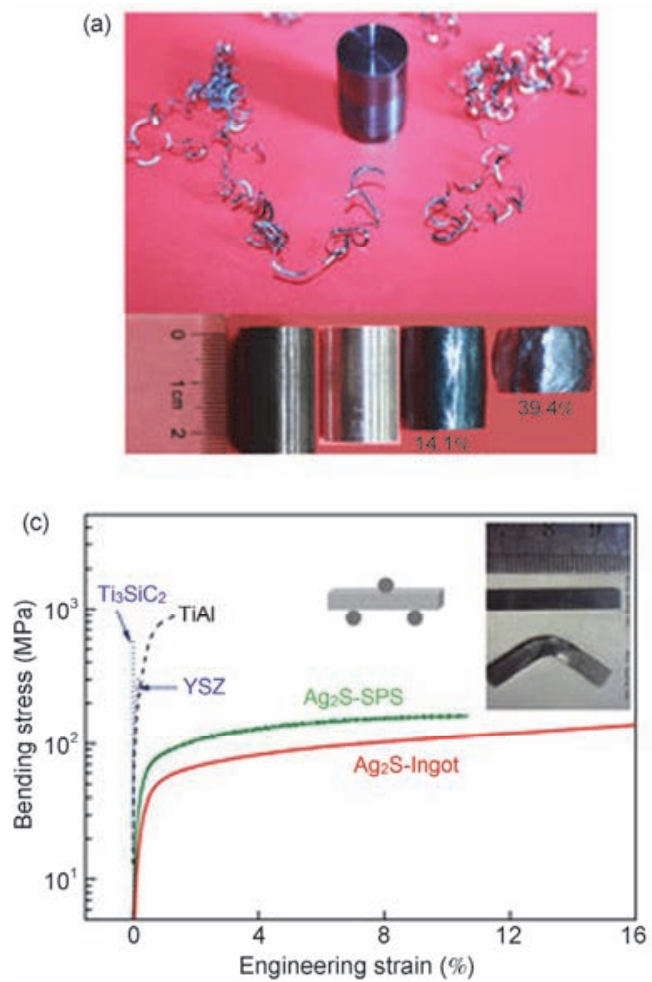
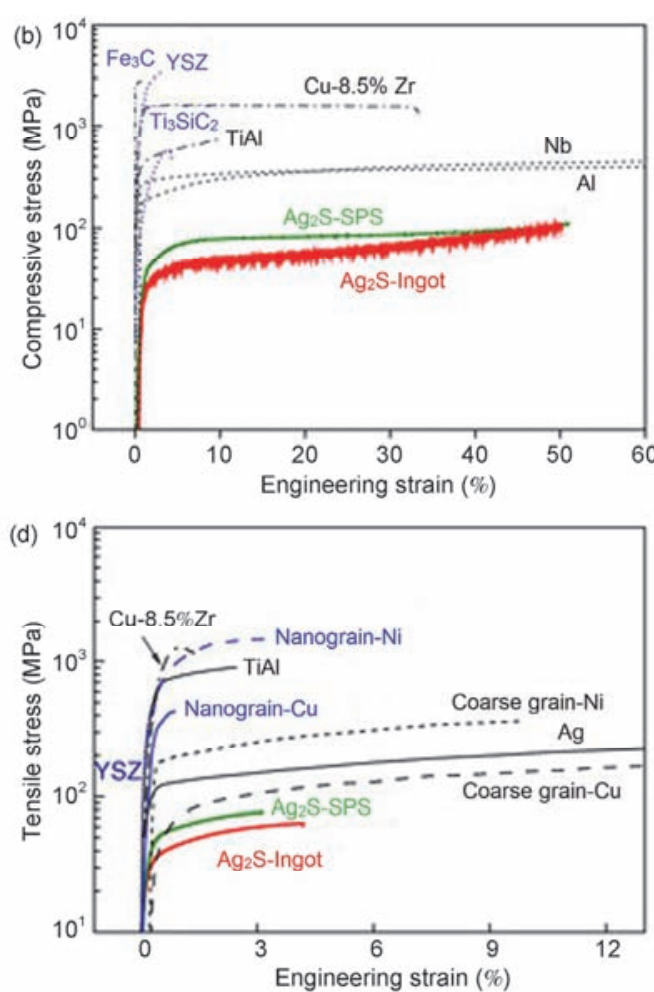

图 1 (网络版彩色)无机半导体 $\alpha-\mathrm{Ag}_{2} \mathrm{~S}$ 材料的室温机械性能. (a) 用于压缩性能表征的 $\alpha-\mathrm{Ag}_{2} \mathrm{~S}$ 圆柱形块体材料及其被捶打后的形变照片. $\alpha-\mathrm{Ag}_{2} \mathrm{~S}$ 的压缩应力曲线 $(\mathrm{b})$, 弯曲应力曲线(c)和拉伸应力曲线 $(\mathrm{d})$ 
展性. 同时, 研究者通过对化学键的分析表明, $\alpha-\mathrm{Ag}_{2} \mathrm{~S}$ 晶 体结构中晶面之间存在相对较弱的原子相互作用, 在滑移 的过程中, $\mathrm{S}$ 原子始终和周围的 6 个 $\mathrm{Ag}$ 原子相互作用, 从而 抑制了无机半导体 $\alpha-\mathrm{Ag}_{2} \mathrm{~S}$ 的断裂, 实现优异的可延展性.

室温可延展的 $\alpha-\mathrm{Ag}_{2} \mathrm{~S}$ 材料与传统的脆性半导体具有 显著的差异, 其具备可折叠、可拉伸、可弯曲等优异的力 学特性, 优异的力学和能带性质使得其在柔性半导体器
件领域具有巨大的应用潜力. 针对柔性电子领域的应用, $\mathrm{Shi}$ 等人 ${ }^{[3]}$ 亦成功制备了 $\alpha-\mathrm{Ag}_{2} \mathrm{~S}$ 块体材料及薄膜材料, 发 现重复弯折并不影响其电学性能. $\alpha-\mathrm{Ag}_{2} \mathrm{~S}$ 兼具优异的类金 属力学性能、可调的电性能及较高的载流子迁移率等特性, 其有望在柔性电子、光电器件、生物医药以及能源存储等 诸多领域引起重大变革. 该工作亦将开启寻找和制备其他 具有类金属力学性能的半导体材料的研究.

\section{参考文献}

1 Lu L, Chen X, Huang X, et al. Revealing the maximum strength in nanotwinned copper. Science, 2009, 323: 607-610

2 Schiøtz J, Tolla F D D, Jacobsen K W. Softening of nanocrystalline metals at very small grain sizes. Nature, 1998, 391: 561-563

3 Shi X, Grin Y, Chen L D, et al. Room-temperature ductile inorganic semiconductor. Nat Mater, 2018, 17: 421-426 